\title{
The Association between Digital Literacy and Social Intelligence
}

\author{
Dr. Chaiyaset Promsri
}

\author{
Rajamangala University of Technology Phra Nakhon, Bangkok, Thailand \\ Corres ponding E-mail: Chaiyaset.p@rmutp.ac.th
}

\begin{abstract}
This present study sought to identify the association between digital literacy and social intelligence. Samples were gathered from 60 undergraduate students studying in management program at a selected public university in Bangkok. A 14-item of Digital Literacy Awareness and a 21 -item of Troms $\phi$ Social Intelligence Scale (TSIS) were utilized to evaluate level of digital literacy and social intelligence, respectively. Analysis of Pearson correlation analysis indicated that the overall digital literacy had no significant relation to social intelligence. Yet, the overall digital literacy was found to have a positive association to social information process $(r=.439, p<0.01)$, and a negative correlation to social awareness at a low level $(r=-.259, p<0.05)$. For the limitations, results of this study showed only relationship between digital literacy and some dimensions of social intelligence, but not causation. This study recommended the further study placing more emphasis on studying cause and effects of these variables. For the originality of research, this study was noteworthy to be the first study in this area that attempted to examine the relationship between digital literacy and social intelligence. Keywords-Digital literacy, digital literacy awareness, Social intelligence.
\end{abstract}

\section{INTRODUCTION}

Digital savvy and emotional and social intelligence are two important factors for job requirements for today's organizations. Nonetheless, technology advancement nowadays can enhance interpersonal communication and social interaction among individuals with both positive and negative outcomes (Adib, Yu, \& Ismail, 2016). A new generation has sufficient knowledge of how to use technology and tends to spend more time on using digital technologies daily, which, on the one hand, can accommodate their life in a rapid way. However, on the other hand, an increase of digital technologies usage can lead to a negative impact (Drago, 2015). An empirical evidence of using too much technology is the decrease of face-to-face communication, which is a critical part of social interaction. This is confirmed by a prior study, which revealed that the extension of time spent on technology and digital tools can distract individuals from a realistic moment and reduce face-to-face interaction leading to the decrease of emotional intelligence (Ramasubba, 2015). A survey of 298 participants also indicated that the use of social media had a negative impact on individual well-being, selfesteem, and relationships (Indvik, 2012). Also, the recent study demonstrated a negative relationship between digital technology savvy and social interaction within a household (McGrath, 2012).
Although digital literacy and skills are important for the era of digital transformation, using only digital literacy is not sufficient to motivate and influence other people to accomplish the goals. Beck and Libert (2017) noted that digital technology can help solve complex business problems and provide useful recommendation for organizational improvement, but human being is still suitable for motivating and leading team to actions, with an understanding that machine may not be replaceable. This demonstrates what known as "social intelligence." In order to effectively manage daily interaction with others, emotional and social intelligence are rated as essential abilities to get others to cooperate with individuals to achieve goals (Albrecht, 2009; Howe, 2019).

Despite digital literacy and emotional and social intelligence was ranked as required essential skills for individuals to fulfill future organization demands, an investigation on the association between these variables is scarce and needs more attention in the future research(Adams Becker, Pasquini, \& Zentner, 2017).Despite similar studies have been conducted in different settings (Marlowe, Bartley, \& Collins, 2017), yet no study attempts to place its emphasis on examining particular variables, which are digital literacy and social intelligence. Also, past studies revealed both positive and negative effects of digital technologies on social skills and social life, and they suggested conducting a further study to examine how digital literacy helped or hindered the 
establishment of social connection (Human Kinetics, 2008). As a result, this present study aimed at investigating association between digital literacy and social intelligence

\section{LITERATURE REVIEWS}

The appearance of digital technologies and digital literacy has brought to the proliferation of study examining the association between digital technology savvy and social connection among people (Danu \& Ugbo, 2017). Gilster (1997) was the first scholar who coined the term digital literacy as "the ability to understand and use information in multiple formats from a wide range of sources when it is presented via computers." Hendricks (2018) concluded that digital literacy is "the ability to navigate various digital platforms and understand, assess and communicate to them." Digital literacy is frequently perceived as "computer skill." Social intelligence is defined as the ability to sense others' feeling and behaviors and establish relationship with them leading to obtain collaboration to accomplish the goals (Albrecht, 2009). Social intelligence is often viewed as "people skill." Silvera et al. (2001) divided social intelligence into three dimensions: social information process (SP), social skills (SS), and social awareness (SA). Social information process refers to the ability to understand and predict others' feelings and behaviors as well as the ability to identify messages transferred during interpersonal communication. Social skills refer to the ability to alterindividual's behaviors to effectively suit to a new social situation and ease to make new friends. Social awareness refers to the ability to ascertain and understand oneself and others' feelings and behaviors in the connection. These two abilities seem to posit on the different continuums, but have shown the relationships in different contexts and environments. The following academic literatures demonstrated an investigation on these two areas and were used as a guideline for developing a research objective and hypothes es.

McGrath (2012) explored the connection between digital technologies within the household and social interaction between individuals. This qualitative study was conducted from four different cases of household using participant observation and semistructured interviews methods. Results demonstrated that digital technologies were negatively associated with social interaction between individuals within the household. Furthermore, findings of this study showed the high level of digital technologies usage could reduce communication within family members.
Drago (2015) conducted an online survey from 100 students at Elon University in the U.S. to identify the level of involvement respondents had with their digital technologies and devices. Results of this survey showed that technology had a negative impact on both quality and quantity of face-to-face interaction. Moreover, more than 90 percent of respondents demonstrated their realization on the negative effect of technology on face-to-face interpersonal communication.

The latest work of Twenge et al. (2018) found that adolescents who spent more time on social media and electronic devices were more likely to have mental health problems, which included depression and suicide, than those who spent less time. This study also found that teenagers increased their time on media screen activities more than non-screen activities since 2010, which may, on the one hand, affect their emotional stability. This study demonstrated the relationship between usage of social media and electronic device, which is part of digital literacy level, and emotional stability. Based on these findings, digital technology apparently had a direct negative impact on emotional intelligence.

Seemingly, using too much digital technology may lead to a shorter attention to the way individuals communicate and connect with others in social interaction. Carlson (2017) noted that "less focus means less listening, less understanding, and more superficiality in how we interact." This implied to the deterioration of emotional and social intelligence.

According to these literature reviews, the research hypothesis was created and proposed as follows:

$H_{1}$ : there was a positive association between digital literacy and social intelligence.

$\mathrm{H}_{2}$ : there was a negative association between digital literacy and social intelligence.

\section{METHODOLOGY}

The study was a quantitative study, which sought to examine the association between digital literacy and social intelligence.Participants of this study were selected from undergraduate students studying in management program at a selected public university in Bangkok. A total of 60 students agreed to participate and completed the survey questionnaire.

To measure digital literacy among respondents, the researcher developed a new scale called "Digital Literacy Awareness", which consisted of 14-item of 5 point rating scale. This instrument was constructed based on related literature reviews. The final version of this scale was constructed to evaluate two essential parts of digital literacy: digital literacy preparation and digital literacy 
self-assessment. To make sure the quality of this newly developed instrument, reliability with Cronbach's alpha test was conducted. The alpha score of 0.83 indicated a high internal consistency of this scale measurement. In addition, The Troms $\varnothing$ Social Intelligence Scale (TSIS) originally developed by Silvera et al. (2001) was modified to use for assessing social intelligence of respondents. This scale measurement contained a 21-item of 5-point rating scale ranging from 1 (strongly disagree) to 5 (strongly agree) encompassing three components: social information process (SP), social skills (SS), and social awareness (SA). The alpha score of this scale was consistent with the original version, which received an acceptable alpha score of 0.66 , according to Nunnally (1978). To explore relationship between digital literacy and social intelligence, Pearson correlation coefficient was conducted.

\section{RESULTS}

Results of this present study demonstrated that the majority of participants were female $(51.7 \%)$ with the average age between $18-25$ years old $(71.7 \%)$.
The association between digital literacy and social intelligence were analyzed by Pearson correlation coefficient. Table 1displayed the relationship between digital literacy and social intelligence and their sub-scales. Overall, this study found no relationship between digital literacy and social intelligence $(r=.153, \mathrm{p}=.244)$.Yet, the overall of digital literacy was found to have a positive association to social information process $(r=.439, \mathrm{p}<$ $0.01)$, and a negative correlation to social awareness at a low level $(r=-.259$, p < 0.05). When analyzed correlation of each dimension of these two variables, findings showed that digital literacy preparationwas positively associated to social information process at an intermediate level $(r=.545, \mathrm{p}<0.01)$ and negatively correlated to social awareness at a low level.Additionally, digital literacy self-assessment was positively related to social information process at a low level $(r=.275$, p < 0.05$)$, but no relationship with other dimensions of social intelligence was found.

Table 1: Correlation between Digital Literacy and Social Intelligence $(n=60)$

\begin{tabular}{|c|r|r|r|r|}
\hline & SIP & SS & SA & SI \\
\hline DLP & $.545^{* *}$ & .083 & $-.312^{*}$ & .191 \\
\hline DLSA & $.275^{*}$ & .056 & -.170 & .095 \\
\hline DL & $.439^{* *}$ & .075 & $-.259^{*}$ & .153 \\
\hline
\end{tabular}

*Significant Level at .05, **Significant Level at .01 DLP $=$ Digital Literacy Preparation, DLSA = Digital Literacy SelfAssessment, SIP = Social Information Process, $S S=$ Social Skills, SA = Social Awareness, SI = Social Intelligence,

\section{CONCLUSION, DISCUSSIONS, AND RECOMMENDATIONS}

This study aimed at examining relationship between digital literacy and social intelligence. Thus, research hypotheses of this study were rejected. Results showed no significant correlation between digital literacy and social intelligence. Yet, this study found a positive link between digital literacy and social information process and a negative correlation between digital literacy and social awareness. These results can be interpreted that when individuals have high ability to navigate various digital platforms and understand, assess and communicate to them, they will have high ability to understand and predict others' feelings and behaviors as well as the ability to identify messages transferred during interpersonal communication. This can be described that individuals tended to have a high level of social information process in relation to digital literacy when they were confined to communicate through the digital platform. In contrast, when individuals have high ability to navigate various digital platforms and understand, assess and communicate to them, they will have low ability to ascertain and understand oneself and others' feelings and behaviors in the connection. The second finding was consistent with prior research, which the negative relationship between digital technology usage and awareness of social interaction was found (McGrath, 2012; Drago, 2015; Twenge et al., 2018)

As this present study found the associations between digital literacy and social information process and social awareness, it suggested that, to have a great life, individuals need to harmonize the use of digital technology, which is based on digital literacy and face-toface social interaction. This study recommends respondents who were tech-digital savvy natives of millennial generation investing more time in building long-term relationship in a non-digital platform (Smith, 2017). This is beneficial for them to increase their emotional and social intelligence as they can improve their understanding of own and other's feelings and 
behaviors. Using too much technology tended not to allow individuals to pay much attention on their emotions especially self-awareness considered as a fundamental of social awareness and relationship management skills (Simples, 2018).

The limitations of this study were a sample size. The next study should extend the sample size and ensure the use of sampling technique to select the samples. In addition, as this study found only relationship between digital literacy and some dimensions of social intelligence, not causation, the further study needs to place more emphasis on investigating cause and effects of these variables.

\section{ACKNOWLEDGEMENT}

I am very thankful to Rajamangala University of Technology Phra Nakhon for publication sponsorship and facility supports.

\section{REFERENCES}

[1] Adams Becker, S., Pasquini, L. A., \& Zentner, A. (2017). 2017 Digital literacy impact study: An NMC Horizon project strategic brief, Volume 3.5, September 2017. Austin, Texas: The New Media Consortium.

[2] Adib, F. I. M., Yu, H., \& Ismail, S. A. (2016). Impact of technology to social interaction among family. Retrieved from https://researchhub.uitm.edu.my/pdf/DrHalida.pdf

[3] Albrecht, K. (2009). Social intelligence: The new science of success. New York, NY: Pfeiffer.

[4] Beck, M. \& Libert, B. (2017). The rise of AI makes emotional intelligence more important. Retrieved from https://hbr.org/2017/02/the-rise-of-ai-makes-emotionalintelligence-more-important

[5] Carlson, C. (2017). Too much tech to connect? 4 strategies to reconnect. Retrieved from https://colettecarlson.com/too-much-tech-to-connect-4strategies-to-reconnect/

[6] Danu, I. V. \& Ugbo, G. O. (2017). Separated household? Effects of personalized communication devices on Nigerian families' communication pattern. https://pdfs.semanticscholar.org/64d0/69d2be19aeb628fdf bc12ca43a0dffb537f8.pdf

[7] Drago, E. (2015). The effect of technology on face-to-face communication. Retrieved from https://www.elon.edu/docs/eweb/academics/communications/research/vol6no1/02Drag oEJSpring15.pdf

[8] Gilster, P. (1997). Digital literacy. New York, NY: Wiley Computer Publishing.

[9] Hendricks, B. (2018). What is digital literacy? definition \& examples. Retrieved from https://study .com/academy/lesson/what-is-digital-literacy definition-example.html

[10] Howe, L. (2019). Future of work requires both digital skills and emotional intelligence. Retrieved from
[11] https://biv.com/article/2019/02/future-work-requires-bothdigital-skills-and-emotional-intelligence

[12] Human Kenetics. (2008). Technology can have positive and negative impact on social interactions. Retrieved from

https://us.humankinetics.com/blogs/excerpt/technology can-have-positive-and-negative-impact-on-socialinteractions

[13] Indvik, L. (2012). Social media fuels low self-esteem, anxiety[study]. Retrieved from https://mashable.com/2012/07/08/social-media-anxietystudy/

[14] Marlowe, J. M., Bartley, A., \& Collins, F. (2017). Digital belongings: The intersections of social cohesion, connectivity and digital media. Ethnicities, 17, 85-10.

[15] doi:10.1177/1468796816654174

[16] McGrath, S. (2012). The impact of digital technology on social interaction within a household. Retrieved from https://www.may noothuniversity.ie/sites/default/files/asset s/document/SiobhanMcGrath.pdf

[17] Nunnally, J. C. (1978). Psychometric theory. New York, NY: McGraw-Hill.

[18] Ramasubbu, S. (2015). Does technology impact a child's emotional intelligence? Retrieved from

https://www.huffpost.com/entry/does-technology-impacta-childs-emotional-intelligence_b_7090968

[19] Silvera, D., Martinussen, M., Dahl, T. I. (2001). The Troms $\varnothing$ Social Intelligence Scale: a self-report measure of social intelligence. Scandinavian Journal of Psychology, 34(4), 313-319.

[20] Simples, V. (2018). Emotional intelligence and technology. Retrieved from

http://www.davidbakeronline.com/emotional-intelligenceand-technology/

[21] Smith, M. (2017). Social media isn't very sociable after all. Retrieved from https://www.carlajohnson.co/socialmedia-isnt-sociable/

[22] Twenge, J. M., Joiner, T. E., Rogers, M. L. \& Martin, G. N. (2018). Increase in depressive systoms, suicide-related outcomes, and suicide rates among U.S. adolescents after 2010 and links to increased new media screen time. Clinical Psychological Science, 6(1), 3-17.

[23] Viana, A., Oliveira, B., Cavalcanti, T., Sousa, K., Mendonça, E., Amaral, I., \& Vasconcelos, U. (2018). Correlation between pyocyanin production and hydrocarbonoclastic activity in nine strains of Pseudomonas aeruginosa. International Journal of Advanced Engineering Research And Science, 5(7), 212223. doi: 10.22161/ijaers.5.7.28 